\title{
Particle in-Flight Behavior and its Determining the Microstructure and Mechanical Properties of Zirconia Based Thermal Barrier Coatings
}

\author{
Kun LIU*, Jun MA \\ Mechanical and Electrical Engineering Institute \\ Zhengzhou University of Light Industry \\ Zhengzhou, China \\ e-mail:6440252@qq.com
}

\author{
Yu BAI \\ Material Science and Engineering institute \\ Xi'an Jiaotong University \\ Xi'an, China \\ e-mail: 280720192@qq.com
}

\begin{abstract}
The present study aims to elaborate the particle inflight behavior during plasma spraying and its significance in determining the microstructure and mechanical properties of plasma sprayed yttria partially stabilized zirconia (YSZ) thermal barrier coatings (TBCs). The as-sprayed YSZ coatings were characterized in terms of the defects (such as pores, unmelted particles and cracks here), hardness and fracture toughness. The results showed that, due to the higher temperature and velocity of in-flight particles in SAPS than that of APS, denser coatings were formed leading to better mechanical properties, including Vickers hardness and fracture toughness. The percentage of defects of microstructure was similar to the temperature and velocity of particles in-flight during plasma spraying. Again, the results were in agreement with that the structural defects had an strongly effect on its mechanical behavior.
\end{abstract}

Keywords-component; in-flight particle; yttria partially stabilized zirconia; microstructure; mechanical properties

\section{INTRODUCTION}

The need for improved energy conversion efficiency has driven a great effort to improve the service temperature of gas turbine engines. One sensible approach is to apply ceramic thermal barrier coatings on the surface of metallic turbine blade in order to reduce its temperature during service [1, 2]. The development of thermal barrier coating systems includes the choice of new materials, structural design and effective preparation methods of coatings [3, 4]. Current TBCs mainly refer to ceramic insulation layers, which are deposited on the metallic component to reduce metal temperatures by as much as $300{ }^{\circ} \mathrm{C}$. Current ceramic insulation layer (top coat) predominantly consists of 6-8 wt. $\% \mathrm{Y}_{2} \mathrm{O}_{3}$ partially stabilized $\mathrm{ZrO}_{2}$ (YSZ). The top coat made either by air plasma spray (APS) or by electron beam physical vapor deposition (EB-PVD).

In general, EB-PVD-TBCs have superior durability but have higher thermal conductivity and higher cost compared with APS-TBCs [5]. However, the APS process is more sensitive to parameter variations. The previous study indicated that there were over 35 main macroscopic parameters that would affect the microstructure of as-sprayed coatings. In addition, some other factors, such as electrode erosion and fluctuations of the powder injection geometry, are uncontrollable. Thus, it is a significant challenge for scientists and engineers to control or tailor the microstructure of as-sprayed coatings.
From a scientific and technological point of view, the velocity and temperature of in-flight particles prior to their impact on to the substrate are two of the primary parameters influencing the microstructure of coatings because they dramatically influence the flattening behavior of the particles and ultimately the microstructure of the coating[6, 7]. Formed by the successive impacting, flattening, and rapid solidification with fully or partially molten splats under complex and interdependent process, it is inevitable that TBCs acquired typical lamellar structures and some other defects (such as pores, cracks and unmelted particles) $[8,9]$. These defects would greatly decrease the mechanical properties of as-sprayed coatings [10,11].

Although many reports which associated with the effect of microstructure on the properties of as-sprayed coatings can be found [12-15], the detailed information on the relationship between particle in-flight behavior, defect and mechanical properties of YSZ coatings is still scarce. In view of the above, the correlation between particle in-flight behavior and coating defects was established and the influence of defects on the mechanical properties of assprayed coatings was further studied.

\section{EXPERIMENTAL PROCEDURE}

\section{A. Materials}

The commercial spray-dried and sintered $\mathrm{ZrO}_{2} 6-8$ wt. $\%$ $\mathrm{Y}_{2} \mathrm{O}_{3}$ powder with $25-110 \mu \mathrm{m}$ and its medium size (D50) 65 $\mu \mathrm{m}$ was used as the feedstock depositing on the austenite stainless steel plates $(10 \mathrm{~mm}$ length $\times 5 \mathrm{~mm}$ width $\times 5 \mathrm{~mm}$ height $)$ directly, which were ultrasonically cleaned and grit-blasted with alumina powder to increase the bonding strength between coatings and austenite stainless steel plates.

\section{B. Plasma Spraying Process}

15 type ceramic coatings with different operating temperature and velocity were fabricated by Metco $9 \mathrm{M}$ air plasma spraying (APS) system and high efficiency supersonic atmospheric plasma spraying (SAPS) system,respectively. The key advantage of supersonic atmospheric plasma spraying system is a novel SAPS gun with a Laval nozzle, and the powder is injected into the plasma jet by an internal injection port, which is inside the nozzle and directed perpendicular to the plasma jet [16]. The plasma spray parameters are summarized in Table 1. 
TABLE I. PARAMETERS OF PLASMA SPRAYING YSZ COATINGS

\begin{tabular}{|c|c|c|c|c|c|c|c|}
\hline Samples & Spray methods & Current (A) & $\begin{array}{c}\text { Primary gas Ar } \\
\text { ( slpm) }\end{array}$ & $\begin{array}{c}\text { Secondary gas } \mathrm{H}_{2} \\
\text { (slpm) }\end{array}$ & $\mathbf{U}(\mathbf{V})$ & $\begin{array}{c}\text { Spray distance } \\
\text { D }(\mathbf{m m})\end{array}$ & $\begin{array}{c}\text { Feed rate } \\
\left(\mathrm{g} \cdot \mathrm{min}^{-1}\right)\end{array}$ \\
\hline $\mathrm{AH} 2$ & APS & 814 & 35.3 & 12.9 & 74 & 100 & 40 \\
\hline AM1 & APS & 808 & 35.3 & 13.2 & 73.9 & 100 & 40 \\
\hline AM3 & APS & 753 & 40.0 & 12.9 & 74.6 & 100 & 40 \\
\hline AL1 & APS & 651 & 47.0 & 12.5 & 72.6 & 70 & 40 \\
\hline AL2 & APS & 648 & 51.7 & 15.0 & 73.8 & 70 & 40 \\
\hline $\mathrm{SH} 2$ & SAPS & 504 & 65.0 & 19.5 & 118 & 90 & 35 \\
\hline SM1 & SAPS & 472 & 75.0 & 21.0 & 124 & 90 & 35 \\
\hline SM2 & SAPS & 487 & 70.0 & 21.0 & 123 & 90 & 35 \\
\hline SL1 & SAPS & 366 & 65.0 & 15.4 & 131 & 90 & 35 \\
\hline SL2 & SAPS & 356 & 60.3 & 15.0 & 125 & 90 & 35 \\
\hline SL3 & SAPS & 312 & 65.2 & 16.7 & 133 & 90 & 35 \\
\hline
\end{tabular}

\section{Specimen Characterization}

During spraying process, the in-flight particles velocity and surface temperature prior to impact onto substrate were monitored using Spray Watch $2 \mathrm{i}$ system (Osier, Finland), the monitor results listed in Table 2. The kinds of defects in coatings were estimated by Image-pro plus (IPP) used scanning electron microscopy (SEM) images at the magnification $800 \times$. In the image analysis, 10 fields of each specimen were acquired randomly for the measurement of kinds of defects.

TABLE II. THE SURFACE TEMPERATURE AND IN-FLIGHT VELOCITY PARTICLES IN THE PLASMA JET

\begin{tabular}{ccc}
\hline Samples & Temperature $\left({ }^{\mathbf{O}} \mathbf{C}\right)$ & Velocity $(\mathbf{m} / \mathbf{s})$ \\
\hline AH1 & $3018.16 \pm 5.0$ & $212.21 \pm 1.48$ \\
AH2 & $3000.94 \pm 3.11$ & $217.88 \pm 3.47$ \\
AM1 & $2992.91 \pm 4.12$ & $217.91 \pm 2.6$ \\
AM2 & $2984.68 \pm 5.14$ & $221.35 \pm 1.87$ \\
AM3 & $2928.62 \pm 2.28$ & $215.03 \pm 1.66$ \\
AL1 & $2899.98 \pm 3.76$ & $213.13 \pm 1.66$ \\
AL2 & $2877.06 \pm 4.68$ & $210.73 \pm 1.87$ \\
AL3 & $2836.14 \pm 3.79$ & $163.69 \pm 2.06$ \\
SH1 & $3400.97 \pm 3.76$ & $481.09 \pm 2.18$ \\
SH2 & $3306.07 \pm 2.65$ & $490.44 \pm 3.84$ \\
SM1 & $3271.25 \pm 2.29$ & $513.25 \pm 2.5$ \\
SM2 & $3278.65 \pm 1.78$ & $486.53 \pm 1.86$ \\
SL1 & $3181.54 \pm 4.18$ & $468.46 \pm 3.33$ \\
SL2 & $3062.12 \pm 5.75$ & $452.88 \pm 3.76$ \\
SL3 & $3034.22 \pm 3.34$ & $440.63 \pm 2.38$ \\
\hline
\end{tabular}

According to the temperature and velocity of particle inflight of 15 types coatings, the specimens of APS- and SAPS-TBCs were divided into 3 groups respectively, that is high temperature and high velocity (AH1, AH2), middle temperature and middle velocity (AM1-AM3), and low temperature and low velocity (AL1-AL3) in APS-TBCs; high temperature and high velocity (SH1,SH2), middle temperature and middle velocity (SM1,SM2), and low temperature and low velocity (SL1-SL3) in SAPS-TBCs. In each groups, based on the numerical values of the temperature and velocity, the specimen numbers formed a descending order. Fig. 1 displayed the microstructure of SH, SM, SL, AH, AM and AL coatings produced by SAPS and APS, respectively.

\section{Indentation Tests and Weibull Analysis}

Vickers micro-hardness and fracture toughness of coatings were all measured with a micro-hardness tester (MicroMET 3 micro-hardness tester, Buehler Ltd., USA). The Vickers indentation were performed on the polished cross section of the coating, which were measured at least 20 times in random different areas with a load of $2.94 \mathrm{~N}$ and 10 $\mathrm{s}$ holding time and keeping at least five times greater than the diagonal length of indentation between consecutive indentations. The Weibull statistical analysis was used to analyze the scatter of micro-hardness data, which distribution characteristic of the mechanical property can reflect the microstructural characteristic of the as-sprayed coatings [1719].The fracture toughness of as-sprayed coatings was determined by [20],

$$
K_{I C}=k_{\text {total }}\left\lceil\frac{P}{a \sqrt{L}}\right\rceil
$$

where coefficient $k_{\text {total }}$ equaled to $k_{p}$ multiplied by 2 ( $k_{p}$ is an empirical constant of fracture toughness in Palmqvist model, $k_{p}=0.0319$ ); $P$ is indentation load, which was $2.94 \mathrm{~N}$ in this study; $L$ is the total surface crack lengths including all the crack around the indent; $a$ is the average Vickers indentation half diagonal size.

\section{RESULTS AND DISCUSSION}

\section{A. Influence of Microstructure of as-Sprayed Coatings}

In view of the spraying characteristic lamellar structure, it is inevitable to form a variety of defects, which were mainly contained pores derived from incomplete contact overlapping for different layers, unmelted areas due to rapidly solidification of lamellae, and cracks arising from the relaxation of thermal or tensile quenching stresses [21]. All above, this microstructure with defects was strongly influenced by the particles behaviors. The different total defects percentage of SAPS- and APS-TBCs under different surface temperature and velocity of spraying particles were showed in Fig. 2. As can be seen from it, when the 
temperature among $3401 \pm 3.76{ }^{\circ} \mathrm{C}-3272 \pm 2.29{ }^{\circ} \mathrm{C}$ and the velocity $514 \pm 2.5 \mathrm{~m} / \mathrm{s}-482 \pm 2.18 \mathrm{~m} / \mathrm{s}$, the total defects percentage was $6.9 \pm 0.16 \%-9.25 \pm 0.29 \%$ (SAPS-TBCs); when the temperature $3182 \pm 4.18{ }^{\circ} \mathrm{C}-2837 \pm 3.34{ }^{\circ} \mathrm{C}$ and the velocity $469 \pm 3.33-441 \pm 2.38 \mathrm{~m} / \mathrm{s}$ (SAPS-TBCs), as well as the temperature $3019 \pm 5.18{ }^{\circ} \mathrm{C}-2985 \pm 5.14{ }^{\circ} \mathrm{C}$ and the velocity among $222 \pm 1.87-213 \pm 1.48 \mathrm{~m} / \mathrm{s}$ (APS-TBCs), the total defects percentage was $13.26 \pm 0.21 \%-11.11 \pm$ $0.36 \%$; when the temperature $2929 \pm 2.28^{\circ} \mathrm{C}-2837 \pm 3.79$ ${ }^{\circ} \mathrm{C}$ and the velocity $164 \pm 2.06-216 \pm 1.66 \mathrm{~m} / \mathrm{s}$ (APS-TBCs), the total defects percentage was $14.01 \pm 0.32 \%-17.15 \pm$ $0.67 \%$. Apparently, with the temperature and velocity increasing, the kinds of defects including pores, unmelted areas and cracks percentage both in the inter- and intra-splat decreased. The relationship among defects and the temperature and velocity of in-flight particles has been summarized in Fig.3, Fig. 4 and Fig. 5, successively. Combined with the results mentioned above between SAPS-
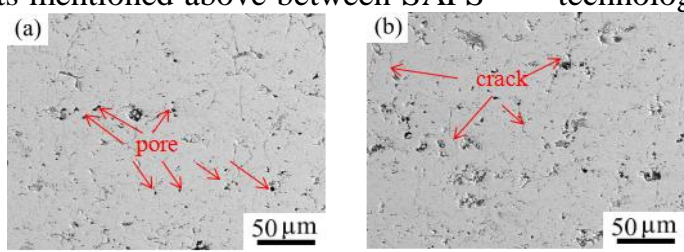

TBCs and APS-TBCs, it is can be explained as follows: On the one hand, owing to higher particle temperature, less partially melted powders, therefore much more fully melted powders incorporated into the coating resulting in the decrease of large pores and unmelted areas. On the other hand, with the increase of velocity of in-flight particle, the larger kinetic energy leading to much better particles flatten behavior and perfect contact of splats, decreased the pores percentage finally, but along with temperature and velocity added, the coatings cracks were not lower as expected. This phenomenon can be explained that the higher temperature formed greater thermal and tensile quenching stress [11]. Moreover, when the temperature and velocity of in-flight particles reached approximately, the content of total flaws with different coatings approached. It has confirmed that spraying process possessed excellent repeatability, which benefited to the stability and repeatability of processing technology.

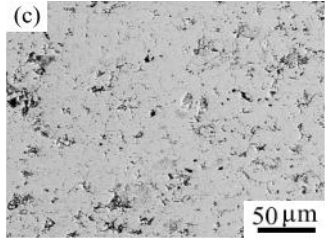

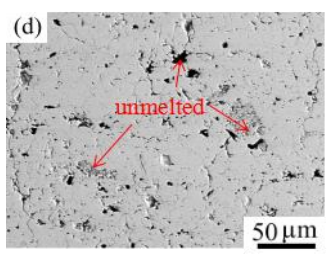

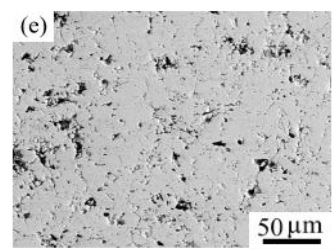

Figure 1. The microstructure of 6 type coatings: (a) SH2 (b) SM1 (c) SL3, which were produced by supersonic atmospheric plasma spraying; (d) AH2 (e) AM2 (f) AL2, which were produced by atmospheric plasma spraying.

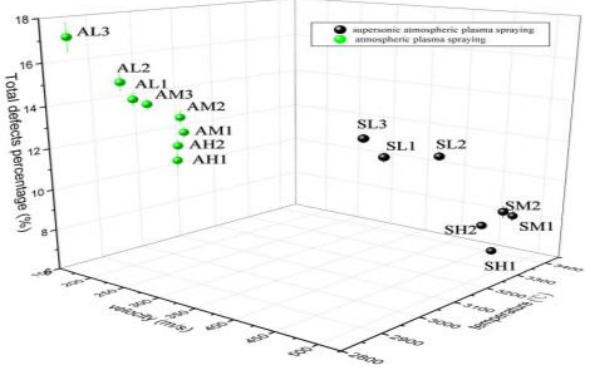

Figure 2. The relationship among temperature and velocity of particles and total defects.

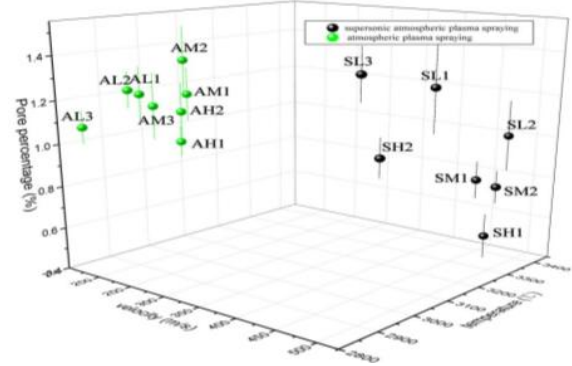

Figure 3. The influence of temperature and velocity of in-flight particles on porosity.

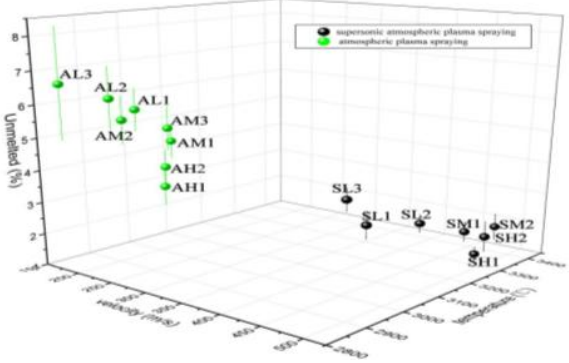

Figure 4. The influence of temperature and velocity of in-flight particles on unmelted.

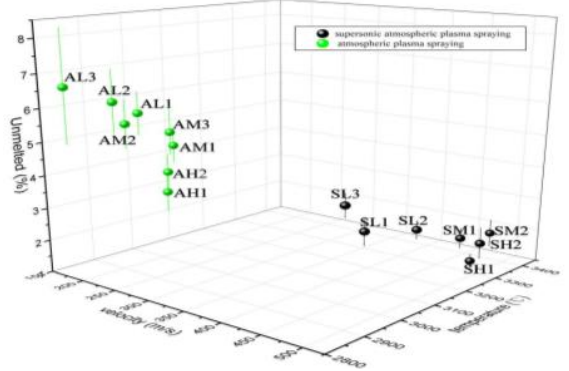

Figure 5. The influence of temperature and velocity of in-flight particles on crack. 


\section{B. Microstructure - Vickers Hardness Relationship}

Of particular interest is knowledge of the Vickers hardness and fracture toughness, which are very significant when attempting to understand or modeling the mechanical behavior or to develop life prediction models of thermal spray coatings used in various applications (e.g. wear, fatigue, and high temperatures) [22, 23]. The current study claimed that the indentation test was essentially a localphase-dependent method and markedly influenced by surface toughness of the samples [24]. Therefore, the probability function of Weibull plots of Vickers hardness could be used to describe the nonuniform microstructure characteristic of two TBCs coatings (see from Fig. 6 and 7). The Vickers hardness of APS specimen is in a range of $687.67 \pm 108.69$

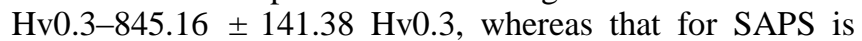
$759.29 \pm 120.94$ Hv0.3-884.12 \pm 84.24 Hv0.3. This phenomenon of higher Vickers hardness in SAPS revealed that it has been greatly improved by the higher temperature and velocity of in-flight particles as a whole, resulted in more densification microstructure in comparison with that of APS-TBCs. Generally, the bigger the Weibull modulus $\mathrm{m}$, the smaller scattering degree of Vickers hardness. The Weibull modulus $m$ of SAPS spanning 6.74-12.4, the APS is 5.58-8.52 yet. In view of the relatively lower hardness of APS-TBCs and lower Weibull modulus m, coupled with the higher total defects and pores, unmelted and cracks percentage, it revealed that microstructure of APS-TBCs is much more nonuniform with less rigidity areas.

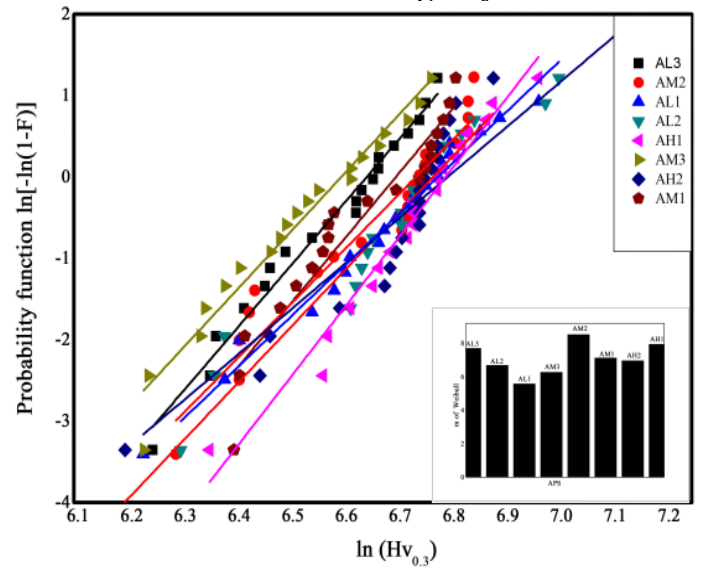

Figure 6. The Weibull plot of Vickers hardness of APS-TBCs.

\section{Microstructure - Fracture Toughness Relationship}

In this Vickers indentation test, performed on polish cross-sections, at least five indentations were made with the same parameter and the load was $5 \mathrm{~N}$, in order to determine the mean crack length and the indentations were examined by SEM. The coating gradually experiences elastic and little plastic deformation, then fractured finally. Once the stress intensity factor $K_{1}$ in representative coatings reached its fracture toughness $\mathrm{K}_{\mathrm{IC}}$, pair of radical cracks usually start to nucleation near the corner angles of Vickers indentation and then presented a semi-ellipse shape along the indentation direction [25, 26]. Fig. 8 and Fig. 9 depicted the relationship between the total defects and fracture toughness, the crack percentage and fracture toughness respectively. It is revealed that the fracture toughness improved with the decreasing of total crack, also the $\mathrm{K}_{\mathrm{IC}}$ values in SAPS were higher than that in APS as a whole. Similar to the relationship between crack percentage and elastic modulus, although with approximate total defects, the $\mathrm{K}_{\mathrm{IC}}$ values of SL1, SL2 and SL3 (SAPS) containing much more crack percentage were higher than AM1 and AM2 (APS). During sintering and cooling of spraying, $\mathrm{ZrO}_{2}$ coatings formed micro-cracks in dispersion distribution on the top layer and/or formed micro-cracks in the process zone of main crack tip when the main crack extending, resulted from phase transformation by stress induced. These small size micro-cracks leaded to the main crack bifurcation or change direction, which increase the effective surface energy in the extension process of the main crack, in addition, it also played a role on dispersion in the crack tip energy, thereby inhibiting the rapid extension of main crack, improve the toughness of the coating.

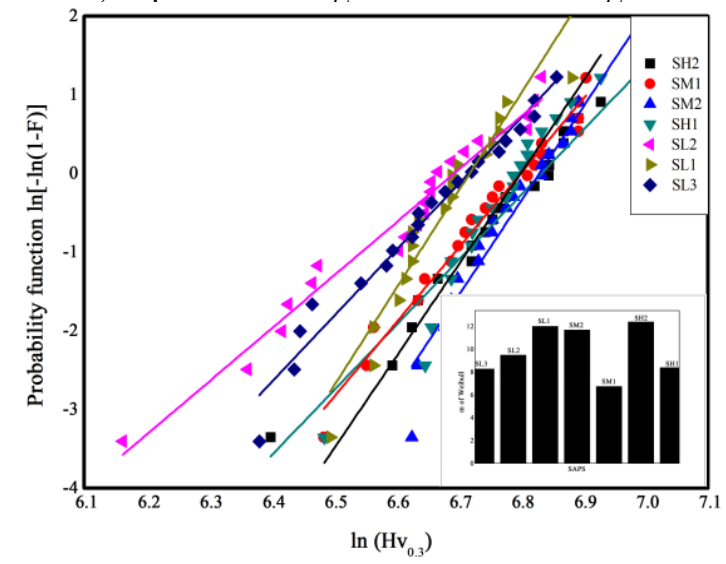

Figure 7. The Weibull plot of Vickers hardness of SAPS-TBCs.

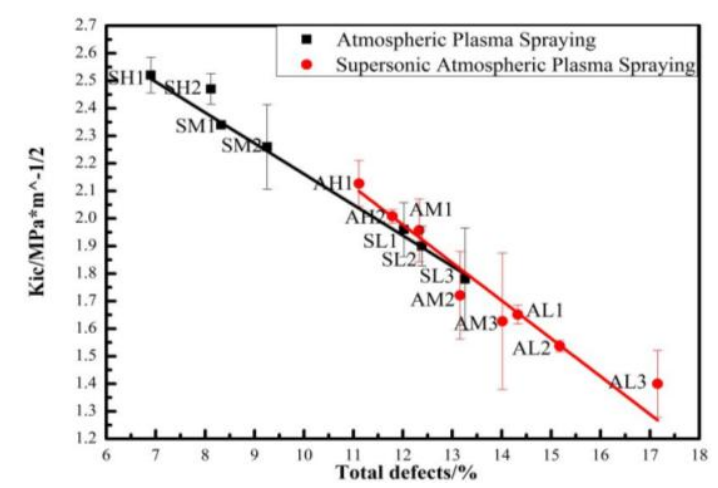

Figure 8. The fracture toughness of SAPS- and APS- TBCs with total defects percentage.

To sum up, the structural defects of SAPS-TBCs were decreased though the improvement of in-flight particle velocity and temperature. According to Vardelle et al. [27], when particle velocity and temperature increased, the flattening degree increased in a linear trend. Because the flattening degree has been greatly advanced which resulted in the effective promotion of bonding area inter-splats and the number of defects owing to the incomplete inter-splat 
contact reduction. As a result, the SAPS-coatings had the lower total defects, higher bonding strength and higher fracture toughness compared with that of APS-coatings.

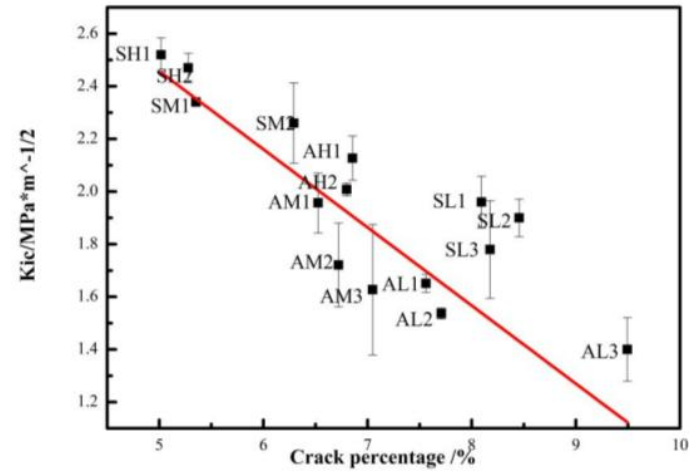

Figure 9. The relationship between fracture toughness and crack content for SAPS- and APS- TBCs.

\section{RESUlTS AND DISCUSSION}

In this paper, the yttria partially stabilized zirconia (YSZ) thermal coatings were deposited by the conventional atmospheric plasma spraying (APS) and the high efficiency supersonic plasma spraying (SAPS). The relationship between microstructure defects and mechanical properties were investigated. The main conclusions are as follows:

(1) The temperature and velocity of in-flight particles of SAPS-TBCs were higher than that of APS-TBCs, which resulted in forming a more densification microstructure with less structural defects and a better mechanical properties (such as Vickers hardness and fracture toughness).

(2) The correlation among the in-flight particle behavior, microstructure and mechanical properties was established in SAPS-TBCs and APS-TBCs. It was found that with the higher temperature and velocity of particles in-flight, the structural defects decreased and furthermore the mechanical properties were enhanced, and vice versa.

(3) The experimental results indicated that a relative higher crack percentage in a reasonable and proper content may improve fracture toughness.

\section{ACKNOWLEDGMENT}

This work was supported by School Scientific Research (Grant No. 13501050034).

\section{REFERENCES}

[1] L.B. Chen, Yttria-stabilized zirconia thermal barrier coatings-a review, Surf. Rev. Lett., 13 (2006), 535-544.

[2] N. Padture, M. Gell, E.H. Jordan, Thermal Barrier Coatings for GasTurbine Engine Applications, Sci. Prog., 296 (2002), 280-284.

[3] Robert Vassen, Xueqiang Cao, Frank Tietz, et al., New Materials for Thermal Barrier Coatings, J. Am. Ceram. Soc., 83 (2000), 2023-2028.

[4] A.G. Evans, D. R. Mumm, J. W. Hutchinson, et al., Mechanisms controlling the durability of thermal barrier coatings, Mater. Sci., 46 (2001), 505-553.

[5] Y. Bai, Z.H. Han, H.Q. Li, et al. High performance nanostructured $\mathrm{ZrO} 2$ based thermal barrier coatings deposited by high efficiency supersonic plasma spraying, Appl. Surf. Sci., 257 (2011), 7210-7216.
[6] P. Fauchais, Understanding Plasma Spraying, J. Phys. D: Appl. Phys., 27 (2004), 86-108

[7] A. Vaidya, V. Srinivasan, T. Streibl, et al, Process maps for plasma spraying of yttria-stabilized zirconia: an integrated approach to design, optimization and reliability, Mater. Sci. Eng. A, 497 (2008), 239-253.

[8] Keshri AK, Patel R, Agarwal A, Comprehensive process maps to synthesize high density plasma sprayed aluminum oxide composite coatings with varying carbon nanotube content, Surf. Coat. Technol., 205 (2010), 690-702.

[9] G. Mauer, R. Vassen, D. Stover, Atmospheric Plasma Spraying of Yttria - Stabilized Zirconia Coatings with Specific Porosity, Surf Coat. Technol., 204 (2009), 172-179.

[10] S. Paul, Assessing Coating Reliability Through Pore Architecture Evaluation, J. Therm. Spray Technol., 19(2010), 779-786.

[11] Y. Bai, Z.H. Han, H.Q. Li, et al., Structure-property differences between supersonic and conventional atmospheric plasma sprayed zirconia thermal barrier coatings, Surf. Coat. Technol., 205 (2011), $3833-3839$.

[12] A. Vaidya, V. Srinivasan, T. Streibl, et al., Process Maps for Plasma Spraying of Yttria-Stabilized Zirconia:An Integrated Approach to Design, Optimization and Reliability, Mater. Sci. Eng. A , 497(2008), 239-253.

[13] S. Sampath, V. Srinivasan, A. Valarezo, et al., Sensing, Control, In Situ Measurement of Coating Properties: An Integrated Approach Toward Establishing Process-Property Correlations, J. Therm. Spray Technol., 18(2009), 243-255.

[14] W. Zhang, S. Sampath, A Universal Method for Representation of InFlight Particle Characteristics in Thermal Spray Processes, J. Therm. Spray Technol., 18(2009), 23-34.

[15] G. Dwivedi, T. Wentz, S. Sampath, et al., Assessing Process and Coating Reliability Through Monitoring of Process and Design Relevant Coating Properties, J.Therm. Spray Technol., 19 (2010), 695-712.

[16] Y. Bai, J.J. Tang, Y.M. Qu, et al., Influence of original powders on the microstructure and properties of thermal barrier coatings deposited by supersonic atmospheric plasma spraying, Part I: Microstructure, Ceram. Int., 39(2013), 5113-5124.

[17] Lima R.S., Kucuk A., Berndt C.C, Bimodal distribution of mechanical properties on plasma sprayed nanostructured partially stabilized zirconia, Mater. Sci. Eng. A, 2002 (327), 224-232.

[18] Siebert B., Funke C., Vaßen R., et al., Changes in porosity and Young's Modulus due to sintering of plasma sprayed thermal barrier coatings, J. Mater. Prog. Technol., 1999(92), 217-223.

[19] Schneider J.M., Bigertelle M., Iost, A, Statistical analysis of the Vickers hardness, Mater. Sci. Eng. A, 1999(262) 256-263.

[20] N.H. Faisal, R. Ahmedb, A.K. Prathurua, et al., An improved Vickers indentation fracture toughness model to assess the quality of thermally sprayed coatings, Eng. Fract. Mech., 128(2014), 189-204.

[21] A. Siao, M. Ang1, Christopher C., et al., A review of testing methods for thermal spray coatings, Int. Mater. Rev., 59 (2014), 179-223.

[22] G.F. Suna, R. Zhouc, J.Zh. Lud, et al., Evaluation of defect density, microstructure, residual stress, elastic modulus, hardness and strength of laser-deposited AISI 4340 steel, Acta. Mater., 84(2015),172-189.

[23] L.H. Gao, H.B. Guo, L.L. Wei, Microstructure and mechanical properties of yttria stabilized zirconia coatings prepared by plasma spray physical vapor deposition, Ceram. Inter., 41(2015), 8305-8311.

[24] H. Li, K.A. Khor, P. Cheang, Young's modulus and fracture toughness determination of high velocity oxy-fuel-sprayed bioceramic coatings, Surf. Coat. Technol., 155 (2002), 21-32.

[25] G.D. Quinn, R.C. Bradt, On the Vickers Indentation Fracture Toughness Test, J. Am. Ceram. Soc., 90(2007) 673-680.

[26] H. Luo, D. Goberman, L. Shaw, M. Gell, Indentation fracture behavior of plasma - sprayed nanostructured $\mathrm{Al}_{2} \mathrm{O}_{3} / 13$ wt. $\% \mathrm{TiO}_{2}$ coatings, Mater. Sci. Eng., 346 (2003) 237-245.

[27] M. Vardelle, A. Vardelle, A.C. Leger, P. Fauchais, D. Gobin, Influence of particle parameters at impact on splat formation and solidification in plasma spraying process, J. Therm. Spray Technol., 4 (1994) 50-58. 